\title{
Persisting hypoxaemia is an insufficient measure of adverse lung function in very immature infants
}

\author{
Ola Hjalmarson, ${ }^{1}$ Hrolfur Brynjarsson, ${ }^{1}$ Staffan Nilsson, ${ }^{2}$ Kenneth L Sandberg ${ }^{1}$
}

${ }^{1}$ Department of Paediatrics, the Sahlgrenska Academy, University of Gothenburg, Gothenburg, Sweden ${ }^{2}$ Department of Mathematical Statistics, Chalmers University of Technology, Gothenburg, Sweden

\section{Correspondence to} Professor Ola Hjalmarson, Department of Paediatrics, the Queen Silvia Children's Hospital, Gothenburg SE-41685, Sweden; ola.hjalmarson@pediat.gu.se

Received 11 June 2013 Revised 27 November 2013 Accepted 1 December 2013 Published Online First 19 December 2013

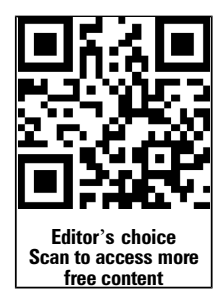

\section{SLinked}

- http://dx.doi.org/10.1136/ archdischild-2013-305768

To cite: Hjalmarson 0 , Brynjarsson $\mathrm{H}$, Nilsson $\mathrm{S}$, et al. Arch Dis Child Fetal Neonatal Ed 2014;99: F257-F262.

\section{ABSTRACT}

Background Bronchopulmonary dysplasia (BPD), defined as protracted neonatal hypoxaemia, is considered a risk factor for respiratory disease in adulthood. The relationship between this diagnosis and the actual lung injury appearing in very immature infants is, however, unknown.

Objectives To compare lung function at term in very immature infants and full-term infants, and to determine how degree and duration of neonatal hypoxaemia are related to other aspects of lung function.

Design and methods All surviving, consecutive infants with gestational age below 28 weeks from a geographically defined area were eligible. The alveolararterial oxygen pressure difference was assessed as a measure of oxygenation failure. At term, functional residual capacity and gas-mixing efficiency were measured by multiple-breath nitrogen washout, and compliance and conductance of the respiratory system by the occlusion method. The results were compared to those in 50 full-term controls.

Main results Thirty-seven of 46 eligible infants were included. The preterm infants differed markedly from the full-term infants in all lung functions tested. Infants diagnosed as having BPD had more compromised lung function than those without, but the latter group differed markedly from the full-term group in functional residual capacity, compliance and gas-mixing efficiency. Only the mechanical variables were correlated to hypoxaemia at 36 weeks postmenstrual age (PMA). Conclusions Infants with gestational age below 28 weeks at birth have remarkably impaired lung function at term, regardless of whether they carry the diagnosis BPD or not. All very immature infants may be at risk of future respiratory disease and should be monitored appropriately.

\section{INTRODUCTION}

A significant proportion of very immature infants develop a chronic lung disease after birth, characterised by impaired alveolisation and capillary development together with interstitial cell proliferation. ${ }^{1}$ Even after intense research, no clear picture of the pathogenesis has emerged. ${ }^{2}$ The possible role played by this condition in the pathogenesis of lung disease in adulthood is attracting interest at present. ${ }^{3}$ The most used clinical designation of the condition is bronchopulmonary dysplasia (BPD), defined as dependency on oxygen supplementation at 28 days of age (mild BPD) or at 36 weeks of postmenstrual age (PMA) (moderate or severe BPD). ${ }^{4}$ This definition was adopted because it had been shown to pinpoint infants with a high risk of developing respiratory disease in infancy. ${ }^{4}$ However, in recent follow-up studies, whether or

\section{What is already known}

Bronchopulmonary dysplasia (BPD) is a risk factor for airway disease later in life.

- Infants with BPD have impaired lung function at term.

\section{What this study adds}

All infants born before 28 weeks of gestational age, and not only those who got the diagnosis bronchopulmonary dysplasia, have as a group disturbed lung function at term. More attention should be paid to the future lung function of al very immature infants.

not BPD is a risk factor for respiratory disease and impaired lung function later in life has been questioned. ${ }^{5-11}$ One reason for the ambiguity may be that the studies have differed in their definitions of BPD, in the gestational ages of the infants studied, in the types of neonatal care, in the lung function tests applied and in the nature of control groups. Another reason may be that BPD is solely defined by hypoxaemia at certain ages, ${ }^{4}$ and the relationship between the disease process that leads to hypoxaemia early in life and the one that may lead to impaired lung function later in life is unknown.

The purpose of this study was to determine how lung function in very immature infants develops up to term, compared to full-term infants, and to try to clarify the relationship between early hypoxaemia and other aspects of lung function at term. A special aim was to investigate whether infants who were classified as having BPD differed in terms of lung function from those who were not. We studied an unselected, geographically defined population of infants with a gestational age at birth of less than 28 weeks. The oxygenation ability was measured as alveolar-arterial oxygen pressure difference and as duration of oxygen supplementation. We assessed functional residual capacity (FRC), mechanics of breathing and gas-mixing efficiency (distribution of ventilation) at term in the immature infants and in a control group of healthy infants born at term.

\section{METHODS}

The study was one part of a project designed to determine how the ability to oxygenate the blood developed in a geographically defined cohort of 
very immature infants with access to advanced neonatal care. Some results on development of oxygenation have been published. $^{12}$

Live-born infants were eligible for the study if (1) the mother lived in a geographically defined area in Gothenburg, Sweden, (2) they were born within defined time periods between 2005 and 2008, (3) they had a gestational age of no more than 27 full weeks and (4) they survived until discharge from hospital. Gestational age was assessed from repeated foetal ultrasound examinations. All infants were born in the same tertiary-care hospital. A neonatologist attended all deliveries, and all infants were treated in the same neonatal intensive care unit.

The target of oxygen supplementation was a transcutaneous oxygen saturation of $88 \%$ to $92 \%$. The average of weekly measurements of the alveolar-arterial difference of oxygen tension $\left(\mathrm{AaDO}_{2}\right)$ over the first month of life was calculated. ${ }^{12}$ We used $\mathrm{AaDO}_{2}$ at 36 weeks PMA as a measure of oxygenation difficulty at that age. In infants with ongoing oxygen supplementation below $30 \%$ at the same age, withdrawal of the oxygen treatment was tried. If the transcutaneous oxygen saturation became below $90 \%$, then the diagnosis BPD was applied. The time from birth until oxygen supplementation was permanently withdrawn was used to assess the duration of hypoxaemia. $\mathrm{AaDO}_{2}$ was assessed by measuring the inspired oxygen fraction together with arterial oxygen and carbon dioxide tensions, by sampling arterial blood or by the transcutaneous route, ${ }^{13}$ and assuming that the respiratory quotient was $1 . .^{12}$

FRC and indices of gas-mixing efficiency were measured by the multiple-breath nitrogen washout method, adapted for newborn infants as described previously. ${ }^{15}$ Efficiency of gas mixing was assessed by calculating a moment ratio $\left(\mathrm{M}_{1} / \mathrm{M}_{0}\right)$ of the course of nitrogen elimination. The zero $\left(\mathrm{M}_{0}\right)$ and first $\left(\mathrm{M}_{1}\right)$ moments of the end-tidal nitrogen concentration were calculated with accumulated expired volume as the independent variable, normalised by FRC, for eight FRC turnovers. ${ }^{15}$ Compliance (Crs) and resistance (Rrs) of the respiratory system were assessed by the single occlusion technique, ${ }^{16}$ with computer-assisted calculations. The results were based on at least three technically satisfactory recordings from washouts and at least five occlusions in each infant. FRC and Crs were normalised by dividing by bodyweight. Conductance, calculated as $1 / \mathrm{Rrs}$, was normalised by FRC to form specific conductance.

The lung function results of the preterm infants were compared to previously gathered data from a cohort of 50 healthy infants who had been vaginally delivered at term and studied at an age of $24-36 \mathrm{~h}$. These data were obtained using identical methods. $^{17}$

The approval of the parents was sought after giving them written and spoken information about the project that was approved by the Regional Research Ethics Board in Gothenburg.

\section{Statistics}

Guided by Levene's test, Student t test or Welch's t test were used for comparisons of means and Spearman's correlation coefficient was calculated to illustrate relationships between variables. With the study sample size, using a t test, we could detect a difference of 0.6 SDs between full terms and preterms at $80 \%$ power using a significance level of $5 \%$. The software packages SPSS Statistics V.17.0.1 and R 2.13.1 ${ }^{18}$ were used.

\section{RESULTS}

Fifty-eight preterm infants were eligible for study and 46 survived until discharge. Parental consent was obtained for 41 infants. We were able to test lung function in 37 at a PMA of 36-45 weeks (mean 40.2 weeks). The full-term controls were studied at $37-42$ weeks (mean 39.8 weeks). Characteristics of the preterm infants are given in table 1 .

\section{Comparison of lung function in preterm} and full-term infants

There were substantial and significant differences between the means of all variables. Preterm infants had lower FRC and compliance, higher specific conductance and less efficient gas mixing than infants born at term (table 2 and figure 1). In the preterm group, the distribution of the variables appeared symmetric around means in histograms, and there was no tendency of any bimodal distribution.

\section{Lung volume, mechanics and performance at term in} preterm infants related to ability of oxygenation

Twenty-four preterm infants fulfilled the criteria for BPD at 36 weeks PMA, and 13 did not. Infants with BPD had lower FRC and higher specific conductance. Also, compliance and gasmixing efficiency appeared to be more compromised in infants with BPD than in those without, but the differences did not reach statistical significance $(p=0.06$ and 0.07 , respectively) (table 2 and figure 1).

Low to moderate correlations, some significant and some not, were found when lung function variables were compared to oxygenation at the first month, to oxygenation at 36 weeks PMA and to duration of oxygen supplementation (table 3 ).

Table 1 Clinical characteristics of infants studied $(n=37)$

\begin{tabular}{lr}
\hline Characteristic & Number (\%) \\
\hline Gender, males & $21(57)$ \\
Gestational age at birth & \\
$23-24$ weeks & $9(24)$ \\
$25-26$ weeks & $17(46)$ \\
27 weeks & $11(30)$ \\
Foetal growth restriction & $7(19)$ \\
Antenatal betamethasone & $33(89)$ \\
Chorioamnionitis ( $n=35)$ & $5(14)$ \\
Caesarean section & $15(41)$ \\
Apgar score 1 min $<7$ ( $\mathrm{n}=36)$ & $24(67)$ \\
Apgar score 5 min <7 ( $\mathrm{n}=36)$ & $10(28)$ \\
Surfactant treated & $23(62)$ \\
Patent ductus arteriosus, treated & $23(62)$ \\
Retinopathy of prematurity, grade 3-4 ( $\mathrm{n}=34)$ & $9(26)$ \\
Septicaemia, verified or suspected & $14(38)$ \\
Days in continuous positive airway pressure (CPAP) & \\
$\quad<30$ & $8(22)$ \\
$30-60$ & $15(41)$ \\
$>60$ & $14(38)$ \\
Mechanical ventilation & $29(78)$ \\
$>7$ days & $13(35)$ \\
Postnatal steroids, by inhalation or systemic & $22(59)$ \\
Bronchopulmonary dysplasia & $24(67)$ \\
severe & $12(32)$ \\
moderate & $11(30)$ \\
none or mild & $14(38)$ \\
\hline *Bscharged with oxygen supplementation & $12(32)$ \\
\hline
\end{tabular}


Table 2 Lung function at term in different cohorts

\begin{tabular}{|c|c|c|c|c|c|}
\hline $\begin{array}{l}\text { Cohort } \\
\text { Units }\end{array}$ & $\mathrm{n}$ & $\begin{array}{l}\text { Functional residual capacity } \\
\mathrm{mL} / \mathrm{kg}\end{array}$ & $\begin{array}{l}\text { Compliance } \\
\mathrm{mL} / \mathrm{cm} \mathrm{H}_{2} \mathrm{O}, \mathrm{kg}\end{array}$ & $\begin{array}{l}\text { Specific conductance } \\
1 / \mathrm{cm} \mathrm{H}_{2} \mathrm{O}, \mathrm{s}\end{array}$ & $\begin{array}{l}\text { Gas-mixing efficiency } \\
\text { Moment ratio }\end{array}$ \\
\hline Full-term controls & 50 & $22.0(0.4)$ & $1.52(0.05)$ & $0.20(0.01)$ & $2.28(0.04)$ \\
\hline All preterms* & 37 & $\begin{array}{l}15.1(0.6) \\
p<0.001\end{array}$ & $\begin{array}{l}0.73(0.04) \\
p<0.001\end{array}$ & $\begin{array}{l}0.27(0.03) \\
p=0.01\end{array}$ & $\begin{array}{l}2.68(0.05) \\
p<0.001\end{array}$ \\
\hline $\begin{array}{l}\text { Preterms } \\
\text { without BPD* }\end{array}$ & 13 & $\begin{array}{l}17.2(1.1) \\
p<0.001\end{array}$ & $\begin{array}{l}0.83(0.07) \\
p<0.001\end{array}$ & $\begin{array}{l}0.20(0.02) \\
p=0.81\end{array}$ & $\begin{array}{l}2.56(0.07) \\
p=0.001\end{array}$ \\
\hline $\begin{array}{l}\text { Preterms } \\
\text { with BPDt }\end{array}$ & 24 & $\begin{array}{l}14.0(0.7) \\
p=0.02\end{array}$ & $\begin{array}{l}0.68(0.04) \\
p=0.06\end{array}$ & $\begin{array}{l}0.32(0.04) \\
p=0.005\end{array}$ & $\begin{array}{l}2.75(0.06) \\
p=0.07\end{array}$ \\
\hline
\end{tabular}

Figure 2 illustrates how the alveolar-arterial oxygen pressure difference was related to FRC and compliance.

When the 13 preterm infants who were not classified as having BPD were compared to the full-term infants, they differed substantially from the full-term group in all functions except specific conductance (table 2 and figure 1 ).
Relationship between previous history and lung function at term

Neither gestational age at birth nor duration of mechanical ventilation was found to be significantly correlated to FRC $(\mathrm{r}=0.31$ and -0.26 , respectively), compliance $(\mathrm{r}=-0.06$ and -0.11$)$ or gas-mixing efficiency $(\mathrm{r}=-0.08$ and -0.04$)$ at term. Two plots
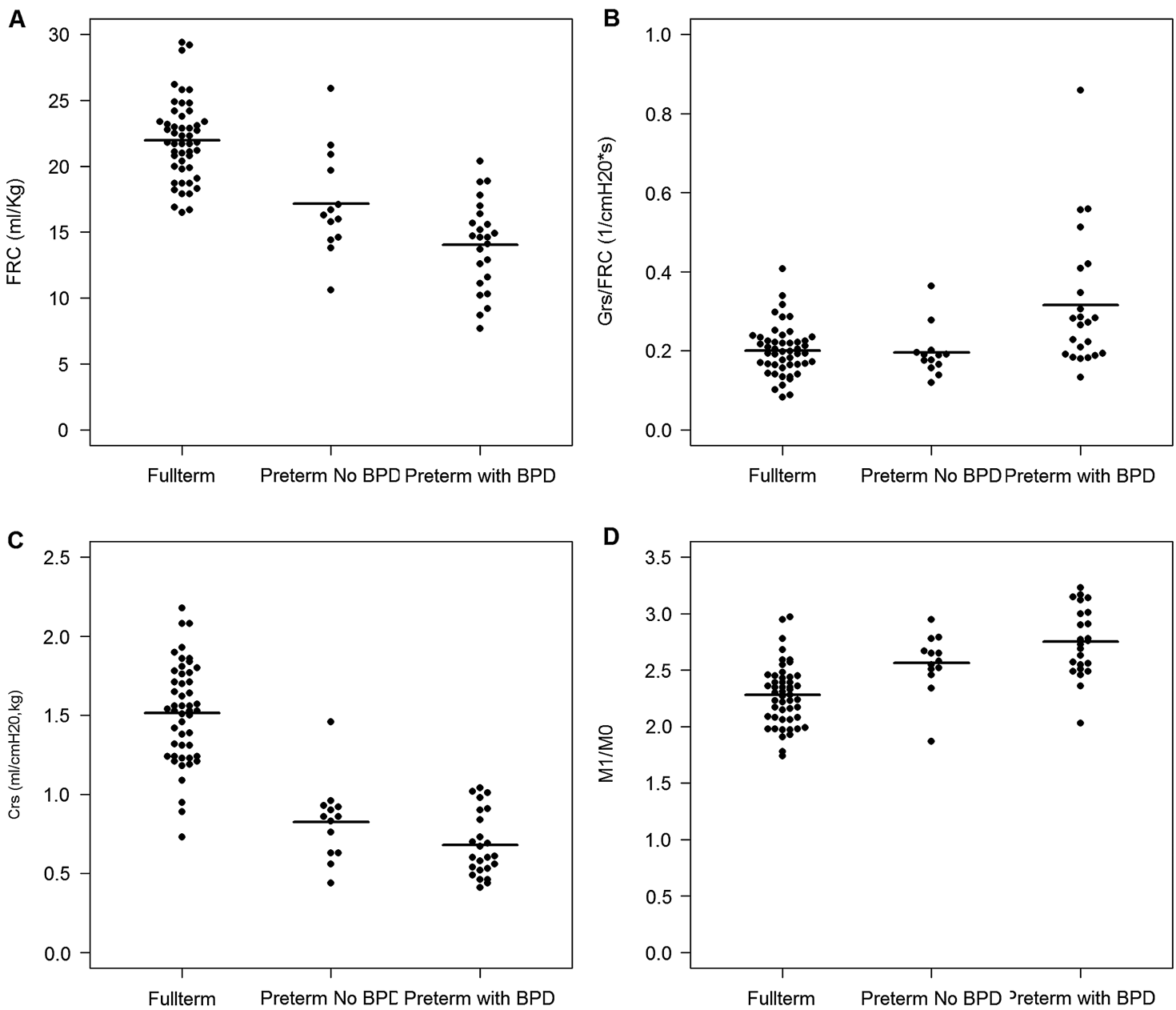

Figure 1 Scatter plots comparing lung function variables obtained at term in healthy full-term infants, in preterm infants without bronchopulmonary dysplasia (BPD) and in preterm infants with BPD. Plot A shows functional residual capacity per kg bodyweight, Plot B shows compliance of the respiratory system per kg bodyweight, Plot $C$ shows specific conductance of the respiratory system and Plot $D$ gas-mixing efficiency in terms of a moment ratio. Horizontal lines denote means. For statistics, see table 2. 
Table 3 Spearman's coefficient of correlation between lung function variables and different measures of oxygenation ability

\begin{tabular}{lllll}
\hline & Functional residual capacity & Compliance & Specific conductance & Gas-mixing efficiency \\
\hline Average $\mathrm{AaDO}_{2}$ first month & -0.40 & -0.19 & 0.32 & -0.12 \\
& $\mathrm{p}=0.01$ & $\mathrm{p}=0.27$ & $\mathrm{p}=0.06$ & $\mathrm{p}=0.48$ \\
$\mathrm{AaDO}_{2}$ at & -0.28 & -0.39 & 0.41 & 0.06 \\
36 weeks PMA & $\mathrm{p}=0.09$ & $\mathrm{p}=0.02$ & $\mathrm{p}=0.01$ & $\mathrm{p}=0.71$ \\
Duration of supplemented oxygen & -0.32 & -0.36 & 0.50 & 0.12 \\
& $\mathrm{p}=0.055$ & $\mathrm{p}=0.03$ & $\mathrm{p}=0.002$ & -0.06 \\
Gestational age at birth & 0.31 & -0.06 & -0.44 & $\mathrm{p}=0.71$ \\
& $\mathrm{p}=0.07$ & $\mathrm{p}=0.74$ & $\mathrm{p}=0.008$ & \\
\hline $\mathrm{AaDO}_{2}$, alveolar-arterial difference of oxygen tension; PMA, post-menstrual age. & & &
\end{tabular}

illustrating the variation are shown in figure 3. There was, however, a correlation between specific conductance and gestational age $(\mathrm{r}=-0.44)$, but not between specific conductance and duration of mechanical ventilation $(r=0.15)$. Infants with low gestational age at birth had higher specific conductance.

\section{DISCUSSION}

This study has shown that, compared to healthy full-term newborns, FRC and the mechanical and gas-mixing properties of the lungs were remarkably different at term in the unselected cohort of surviving infants born after 23-27 weeks of gestation. The result shows that human lungs develop differently in several ways when they are exposed to extrauterine conditions from a very immature state compared to when maturation takes place in utero. We have previously reported that more mature preterm infants, with or without BPD, differ from infants born at term regarding FRC, compliance and gas-mixing efficiency. ${ }^{17}{ }^{19}$ Similar results have also been found by others. ${ }^{20-23}$ However,
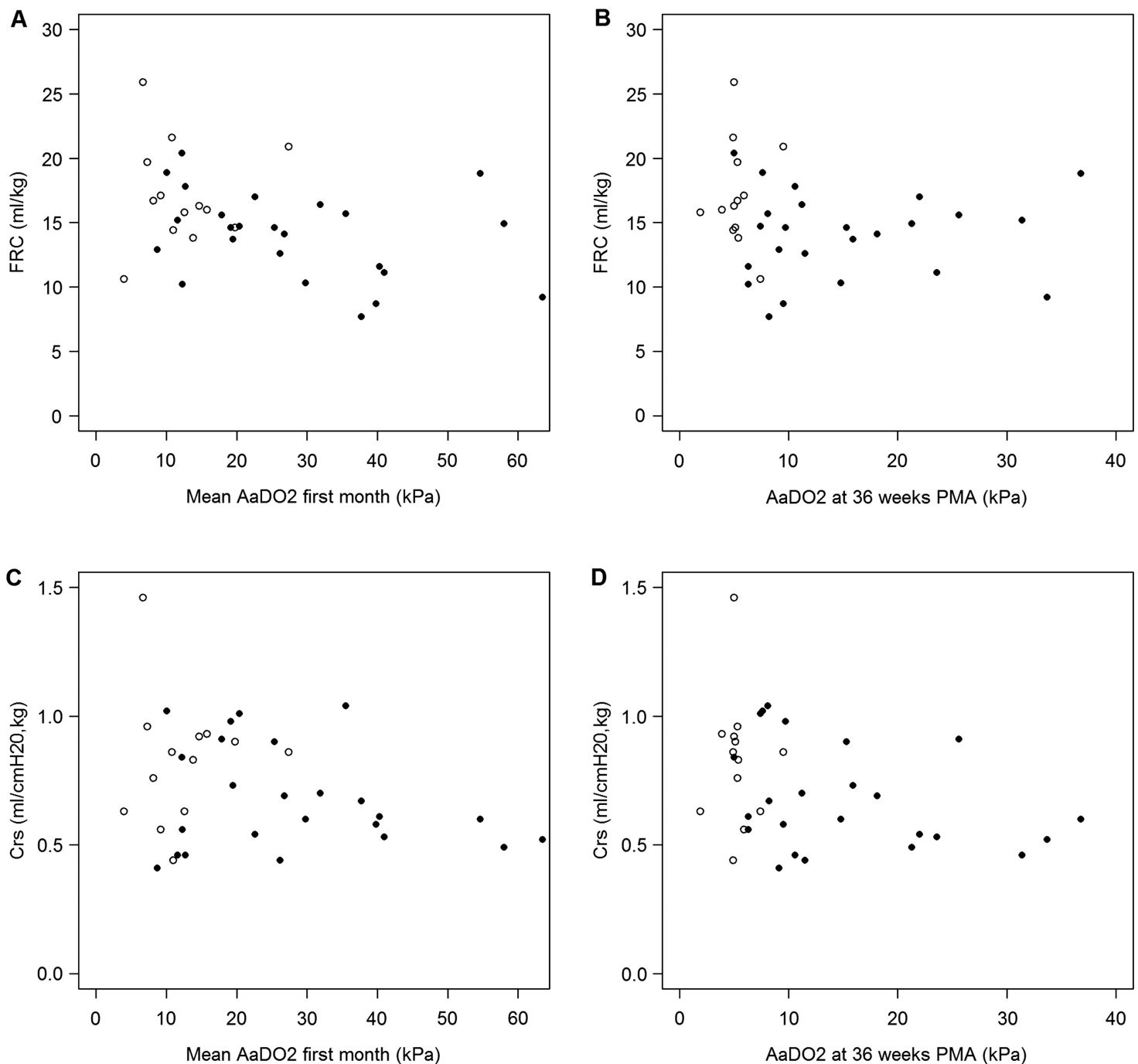

Figure 2 Functional residual capacity and compliance at term related to alveolar-arterial oxygen pressure difference at first month and at 36 weeks postmenstrual age (PMA). $\mathrm{AaDO}_{2}$, alveolar-arterial difference of oxygen tension; FRC, functional residual capacity; Crs, compliance of the respiratory system. Filled and empty symbols denote infants with and without bronchopulmonary dysplasia, that is, needed supplementary oxygen at 36 weeks PMA. 
Figure 3 Functional residual capacity and compliance at term related to gestational age at birth and number of days on ventilator, respectively. FRC, Functional residual capacity; Crs, Compliance of the respiratory system. Filled and empty symbols denote infants with and without bronchopulmonary dysplasia, that is, needed supplementary oxygen at 36 weeks postmenstrual age.
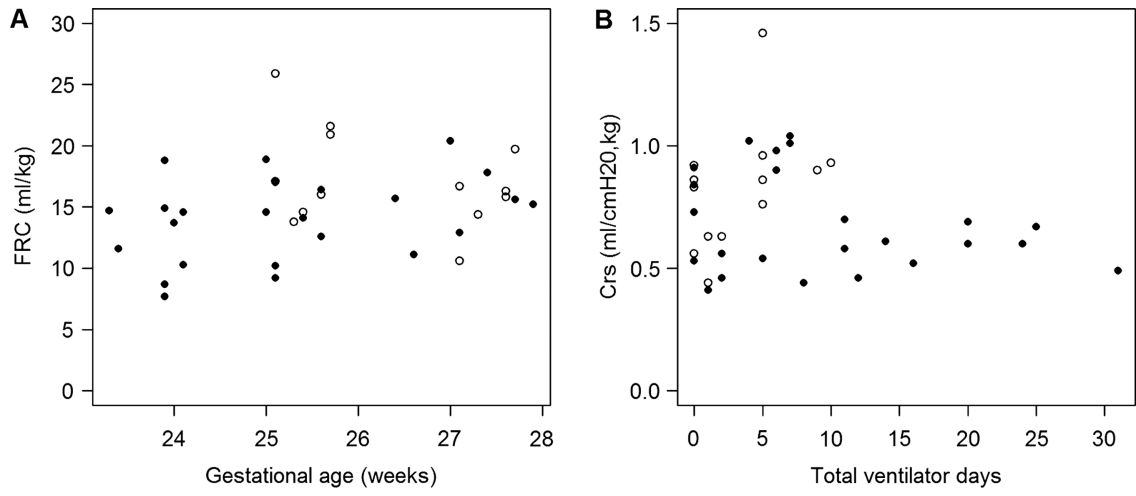

the extent of the deviations found in this study was greater than in our previous report. ${ }^{17}$ It may illustrate that the degree of immaturity at birth or the duration of exposure to some extrauterine condition determines the degree of lung injury.

The distribution of the lung function variables was approximately normal and there was no visible tendency of the material to consist of one 'healthy' and one 'diseased' subgroup for any variable. The low FRC and compliance observed is consistent with the histological picture of chronic lung disease of prematurity, with few but large alveoli and a cell-rich interstitial space. ${ }^{1}$ Specific conductance is mainly a measure of the patency and dimensions of major airways in relation to lung size. The results of this study may seem paradoxical, as the airways appeared to be more-and not less-conductive in preterm infants than in term infants. However, similar results have been reported before. ${ }^{17}{ }^{24}$ It may reflect the fact that the normal balance between airway growth and development of peripheral airspaces is changed, mainly by disturbed formation of normal acini. ${ }^{1}$ In our material, as in a previous study, ${ }^{19}$ the elevated specific conductance was confined to the group with BPD.

It was also evident that gas mixing was less efficient in the preterm infants than in the full-term controls. We have found this before in more mature preterm infants. ${ }^{17}{ }^{19}$ Gas mixing is a complicated process; it mainly takes place in the periphery of the lung, but it is also influenced by other factors such as pattern of breathing. ${ }^{25}$ We interpret our findings as being a sign of different acinar structures in preterm and full-term infants at term.

Although it often does not start in the first days of life, hypoxaemia is a predominant sign in the first period of extrauterine life in very immature infants. ${ }^{12} 26$ The mechanisms involved are remarkably little investigated. Because oxygen supplementation can elevate blood oxygen tension, the cause is to be found in a diffusion barrier or in inefficient matching of ventilation to perfusion. Inflammatory oedema and structural changes (local or general) in terminal airspaces, in the capillary network, or in interstitial tissue may affect oxygenation of blood in the lungs. However, hypoxaemia will fade in time. Instead, airway dysfunction becomes prevalent in infancy and childhood. $.^{5-8} 27-31$ It is not clear how the process leading to long-standing hypoxaemia and the one that ends in late airway disease are linked. ${ }^{6}$ In this study, when the degree of oxygenation failure was expressed as alveolar-arterial oxygen pressure difference over the first month of life, at 36 weeks of PMA or as duration of oxygen supplementation, the relationship between FRC and the mechanical parameters was weak or moderate at best, and no correlation with gas-mixing efficiency was found (table 3). The results show that the pathological process leading to hypoxaemia does not strictly parallel to other injurious patterns.
There is only one criterion for the diagnosis of BPD and that is inability to oxygenise the blood at certain time points. ${ }^{4}$ When the preterm infants in this study were sorted into one BPD group with persistent need of oxygen supplementation at 36 weeks PMA, and another without, there was a difference between groups regarding lung function variables (table 2). However, another important result was that there was a pronounced difference between the preterm infants without BPD on one hand and the full-term infants on the other in all physiological variables except specific conductance (figure 1). The difference was greater than between infants with and without BPD (table 2). This illustrates that not only does the group of very immature infants that needs supplemented oxygen over long time have functionally compromised lungs, but the whole set of very immature infants shares the fate of having adverse lung function at term. BPD, that is, hypoxaemia, is only one manifestation of the chronic lung disease affecting preterm infants.

That the most immature infants (below 26 weeks of gestation) without BPD may also have reduced lung function later in life was shown in the EPICure study. ${ }^{5}$ At 11 years of age, children who were classified as having had BPD had more reduced lung function than those who had had no BPD, but the difference between the group with no BPD and their classmates was also very pronounced. Also, in other recent follow-up studies, the main difference has not been between former BPD and no BPD, but between ex-preterm infants and full-term infants. ${ }^{7} 11 \quad 3132$ This shows that even infants with no BPD are at risk of developing chronic lung disease, although it may be lower than for those who have had oxygen supplementation for a long time. Whether or not any lung function variable that can be assessed before discharge would be a better predictor of airway pathology than BPD remains to be established.

In summary, infants with very low gestational age at birth not only have a strong tendency to develop hypoxaemia, but also have other manifestations of pulmonary dysfunction when studied at term. Different measures of hypoxaemia, including the diagnosis BPD, do not reflect the full picture of the lung disease. It is important that future research should improve our understanding of the pathogenesis of the airway disease that dominates the clinical picture at school age and beyond, especially as airway disease may develop after term, ${ }^{27}$ and could then be a target for preventive measures or more effective treatment. Since many children who are born as very immature infants may have airway disease that is undertreated at present, ${ }^{5}$ it is important that all such infants-regardless of whether or not they are classified as having BPD—should be regarded as being at risk of developing chronic airway disease and be monitored closely and treated appropriately. 
Acknowledgements We are grateful to Kristina Hellgren, Gunilla Steen and Anna-Lena Fransson for skilful technical assistance.

Collaborators Anna-Lena Fransson; Kristina Hellgren; Gunilla Steen.

Contributors $\mathrm{OH}, \mathrm{HB}$ and KLS contributed to the design of the study, and all authors contributed to the analysis and interpretation of the results, revised the manuscript and approved the final version. In addition, SN reviewed the statistics. $\mathrm{OH}$ drafted the manuscript.

Funding Grants were received from the Swedish Heart and Lung Association, the Frimurare Barnhuset Foundation and Government Grants to University Hospitals in Sweden.

Competing interests None.

Ethics approval The Regional Research Ethics Board in Gothenburg.

Provenance and peer review Not commissioned; externally peer reviewed.

\section{REFERENCES}

1 Coalson JJ. Pathology of bronchopulmonary dysplasia. Semin Perinatol 2006;30:179-84

2 Merritt TA, Deming DD, Boynton BR. The 'new' bronchopulmonary dysplasia: challenges and commentary. Semin Fetal Neonatal Med 2009;14:345-57.

3 Krauss-Etschmann S, Bush A, Bellusci S, et al. Of flies, mice and men: a systematic approach to understanding the early life origins of chronic lung disease. Thorax 2013:68:380-4.

4 Jobe AH, Bancalari E. Bronchopulmonary dysplasia. Am J Respir Crit Care Med 2001:163:1723-9.

5 Fawke J, Lum S, Kirkby J, et al Lung function and respiratory symptoms at 11 years in children born extremely preterm: the EPICure study. Am J Respir Crit Care Med 2010;182:237-45

6 Lum S, Kirkby J, Welsh L, et al. Nature and severity of lung function abnormalities in extremely pre-term children at 11 years of age. Eur Respir J 2011;37:1199-207.

7 Cazzato S, Ridolfi L, Bernardi F, et al. Lung function outcome at school age in very low birth weight children. Pediatr Pulmonol 2013;48:830-7.

8 Kaplan E, Bar-Yishay E, Prais D, et al. Encouraging pulmonary outcome for surviving, neurologically intact, extremely premature infants in the postsurfactant era. Chest 2012;142:725-33.

9 Brostrom EB, Thunqvist P, Adenfelt $\mathrm{G}$, et al. Obstructive lung disease in children with mild to severe BPD. Respir Med 2010;104:362-70.

10 Smith LJ, McKay KO, van Asperen PP, et al. Normal development of the lung and premature birth. Paediatr Respir Rev 2010;11:135-42.

11 Schmalisch G, Wilitzki S, Roehr CC, et al. Development of lung function in very low birth weight infants with or without bronchopulmonary dysplasia: longitudinal assessment during the first 15 months of corrected age. BMC Pediatr 2012;12:37.

12 Hjalmarson $\mathrm{O}$, Brynjarsson $\mathrm{H}$, Nilsson $\mathrm{S}$, et al. Spectrum of chronic lung disease in a population of newborns with extremely low gestational age. Acta Paediatr 2012:101:912-18
13 Sandberg KL, Brynjarsson $\mathrm{H}$, Hjalmarson O. Transcutaneous blood gas monitoring during neonatal intensive care. Acta Paediatr 2011;100:676-9.

14 Nelson NM, Prodhom LS, Cherry RB, et al. Pulmonary function in the newborn infant. V. Trapped gas in the normal infant's lung. J Clin Invest 1963:42:1850-7.

15 Shao H, Sandberg K, Sjoqvist BA, et al. Moment analysis of multibreath nitrogen washout in healthy preterm infants. Pediatr Pulmonol 1998;25:52-8.

16 Lesouef PN, England SJ, Bryan AC. Passive respiratory mechanics in newborns and children. Am Rev Respir Dis 1984;129:552-6.

17 Hjalmarson 0, Sandberg K. Abnormal lung function in healthy preterm infants. Am J Respir Crit Care Med 2002;165:83-7.

18 R Development Core Team. R: A language and environment for statistical computing. Vienna, Austria: R Foundation for Statistical Computing, 2011.

19 Hjalmarson 0, Sandberg KL. Lung function at term reflects severity of bronchopulmonary dysplasia. J Pediatr 2005;146:86-90.

20 Gappa M, Pillow JJ, Allen J, et al. Lung function tests in neonates and infants with chronic lung disease: lung and chest-wall mechanics. Pediatr Pulmonol 2006:41:291-317.

21 Hulskamp G, Pillow JJ, Dinger J, et al. Lung function tests in neonates and infants with chronic lung disease of infancy: functional residual capacity. Pediatr Pulmonol 2006;41:1-22.

22 Pillow JJ, Frerichs I, Stocks J. Lung function tests in neonates and infants with chronic lung disease: global and regional ventilation inhomogeneity. Pediatr Pulmonol 2006;41:105-21.

23 Hulskamp G, Lum S, Stocks J, et al. Association of prematurity, lung disease and body size with lung volume and ventilation inhomogeneity in unsedated neonates: a multicentre study. Thorax 2009;64:240-5.

24 Stocks J, Godfrey S. Specific airway conductance in relation to postconceptional age during infancy. J Appl Physiol 1977:43:144-54.

25 Engel LA. Gas mixing within the acinus of the lung. J Appl Physiol 1983;54:609-18.

26 Laughon $\mathrm{M}$, Allred EN, Bose $\mathrm{C}$, et al. Patterns of respiratory disease during the first 2 postnatal weeks in extremely premature infants. Pediatrics 2009;123:1124-31.

27 Hoo AF, Dezateux C, Henschen M, et al. Development of airway function in infancy after preterm delivery. J Pediatr 2002;141:652-8.

28 Doyle LW. Respiratory function at age 8-9 years in extremely low birthweight/very preterm children born in Victoria in 1991-1992. Pediatr Pulmonol 2006;41:570-6.

29 Korhonen P, Laitinen J, Hyodynmaa E, et al. Respiratory outcome in school-aged, very-low-birth-weight children in the surfactant era. Acta Paediatr 2004;93:316-21.

30 Hacking DF, Gibson AM, Robertson C, et al. Respiratory function at age 8-9 after extremely low birthweight or preterm birth in Victoria in 1997. Pediatr Pulmonol 2013;48:449-55.

31 Vrijlandt EJ, Gerritsen J, Boezen HM, et al. Lung function and exercise capacity in young adults born prematurely. Am J Respir Crit Care Med 2006;173:890-6.

32 Smith LJ, van Asperen PP, McKay KO, et al. Post-natal corticosteroids are associated with reduced expiratory flows in children born very preterm. J Paediatr Child Health 2011:47:448-54 